\title{
Reforma trabalhista, revolução digital e violência política: último prego no caixão do trabalho do telejornalista
}

\author{
Érica C. P. Lima-Souza' \\ Carolina Maria Mota-Santos ${ }^{2}$ \\ Antonio Carvalho Neto ${ }^{3}$
}

\section{Resumo}

O trabalho dos jornalistas está entre os mais atingidos pela Revolução 4.0, crise agravada pela reforma trabalhista brasileira. Este estudo discute os impactos desse cenário para jornalistas de emissoras de televisão tradicionais e da internet. Foram entrevistados 18 telejornalistas, 8 de TVs tradicionais e 10 da internet; e 7 dirigentes sindicais. Emissoras tradicionais impõem aos jornalistas novos contratos de trabalho, com ampliação da jornada. A violência do público é um novo fator para cogitarem abandono da profissão, auto emprego e empreendedorismo. Os jornalistas das emissoras da internet têm jornada ainda maior, remuneração menor e muito mais funções.

\section{Palavras-Chave}

Indústria 4.0; Jornalismo tradicional; Jornalismo na internet; Relações de Trabalho; Precarização do trabalho.

Labor reform, digital revolution and political violence: the last nail in the coffin of the newscaster's work

\begin{abstract}
Journalists' work is among the hardest hit by Revolution 4.0, a crisis aggravated by Brazilian labor reform. This study discusses the impacts of this scenario for journalists from traditional television stations and the internet. We interviewed eighteen television journalists, 8 from traditional TVs and 10 from the internet and 7 union leaders. Traditional broadcasters impose new employment contracts on journalists, with extended working hours. Public violence is a new factor that drives journalists to consider abandoning the profession, self-employment and entrepreneurship. Journalists at Internet broadcasters work even more hours, get lower pay and perform more tasks.
\end{abstract}

\section{Keywords}

Industry 4.0; Traditional journalism; Internet journalism; Labor relations; Precarious work. 
Artigo recebido em junho 2020

Artigo aprovado em agosto de 2020

\section{Introdução}

A revolução digital, ou Indústria 4.0, vem provocando profundas mudanças nos fundamentos dos sistemas de produção de bens e serviços. O trabalho por meio de plataformas digitais se intensificou sobremaneira. Ao mesmo tempo em que cria boas oportunidades de negócios e de novos modelos de trabalho digital, também favorece a precarização do trabalho existente e a criação de novos empregos precários (DUNN, 2017; SOUSA, 2019).

O Uber e a AirBnB são empresas que se tornaram símbolos desse fenômeno. Como salienta Pochmann (2016), a precarização, que já vinha se estabelecendo ao longo dos anos, somada ao atual progresso tecnológico (cujas inovações alcançaram escala e rapidez sem precedentes), ao aumento da quantidade de desempregados e ao desmonte das leis trabalhistas deu origem à "uberização". Esse termo, tomado como sinônimo de trabalho precário, é uma referência e uma crítica à empresa "Uber" (POCHMANN, 2016). Disfarçada sob a ideia de empreendedorismo, a empresa se isenta da responsabilidade dos direitos trabalhistas dos prestadores de serviços a ela vinculados (LEME; RODRIGUES, 2017; PINHEIRO, PAULA SOUZA; GUIMARÃES, 2020).

A reforma trabalhista brasileira (promulgada em 2017) permitiu a substituição de contratos formais de trabalho (que eram via de regra menos precários), flexibilizando as formas de contratação, tornando-as mais precárias. Muitos trabalhadores passaram para regimes de Pessoa Jurídica (PJ, a chamada "pjotização") ou Microempreendor Individual (MEI) para continuarem prestando serviços às empresas, perdendo todos os direitos que tinham como trabaIhadores formais, como férias, décimo terceiro, FGTS e previdência (KREIN, 2018; PATRICK; ELKS, 2015). 
A precarização do trabalho dos jornalistas se insere nesse contexto. Essa categoria foi uma das primeiras a sentir os efeitos socioeconômicos do processo de evolução tecnológica e desregulamentação trabalhista (DANTAS, PINHEIRO, DA SILVA, BELTRAME; DAVID, 2017; PATRICK; ELKS, 2015). Por isso, torna-se relevante compreender a conjuntura em que ocorre. No caso do telejornalismo, foco deste trabalho, a web possibilitou, por exemplo, o surgimento de canais de TV da internet. Muitos profissionais migraram para esse ambiente, desempenhando muito mais funções e com menor remuneração, ou seja, sob condições de trabalho mais precárias (RODEMBUSCH; BONAMICO, 2017). A reforma trabalhista acentuou a crise já vivenciada pelo setor. Somou-se a ela, o crescimento da violência contra os jornalistas. De 2018 para 2019, houve um aumento de 50\% no número de ataques contra esses profissionais (FENAJ, 2020). O contexto político do país tem agravado a situação, contribuindo para que os jornalistas cogitem o abandono da profissão.

Geralmente, as pesquisas brasileiras acerca da temática têm um enfoque mais voltado aos efeitos da tecnologia sobre a produção de notícias e distribuição, aos processos comunicativos propriamente. Sobre os aspectos relacionados ao trabalho, às transformações das atividades, especialmente relacionadas à jornada, remuneração, crise profissional e impactos sobre a carreira, a literatura é rara. E mais rara ainda compreendendo TV Tradicional e da Internet e discutindo contextos atuais, como reforma trabalhista e violência. O presente estudo pretende, portanto, preencher esta lacuna, discutindo as atividades e os desafios de telejornalistas de emissoras de TV Tradicionais e da Internet, diante da revolução digital, da reforma trabalhista e do atual cenário político brasileiro.

\section{A Indústria 4.0 e o Trabalho dos Jornalistas}

No Brasil, a TV, meio de comunicação mais presente no dia a dia das pessoas, foi se modificando ao longo dos anos, acompanhando as 
evoluções tecnológicas (WOLFF, 2015), numa convergência cada vez maior com computadores e celulares. A web não se restringiu a um papel paralelo às mídias, ela também se tornou um veículo de comunicação. Há de se pontuar que, com as novas tecnologias, sistemas de produção e veiculação de vídeos da internet ganharam diversos nomes (IPTV, WEB TV, VOD, OTT, etc.). Não há ainda regulação específıca para a TV da internet, bastando ter a descrição de atividade econômica semelhante à Netflix - "Portais, provedores de conteúdo e outros serviços de informação na internet" - para veicular e comercializar conteúdos audiovisuais pela web (RODEMBUSCH; BONAMICO, 2017).

Contudo, há diferenças significativas entre a TV Digital e a TV da Internet. A TV Digital se refere ao ambiente virtual, englobando o processo de convergência para o modo digital, que tem sido realizado pelas emissoras tradicionais. A TV da Internet diz respeito às TVs que surgiram no ambiente virtual, não houve migração nesse caso.

Sendo assim, toda TV da internet é digital por estar no meio digital, mas nem toda TV digital é da internet, uma vez que pode ser uma TV tradicional que migrou sua programação para a internet, não gerou sua programação lá, não nasceu nesse ambiente (FERREIRA; BIANCHETTI, 2018). Foi com base nessa diferenciação que este estudo buscou investigar profissionais jornalistas que trabalham em emissoras tradicionais e emissoras da internet. A tecnologia permite que qualquer pessoa emita conteúdos, inclusive informativos, sem a obrigação de uma intermediação profissional. Isso tem trazido inquietações a jornalistas do setor no que diz respeito à própria continuidade da profissão (SIMON et al. 2019).

Ferreira e Bianchetti (2018) citam algumas diferenças e mudanças no trabalho de apresentadores de televisão da internet. Esse "novo jornalista" precisa lidar com a interação em tempo real, a necessidade de se adaptar à linguagem, entre outros. É também sobre o trabalho do profissional de televisão que Rodembusch e Bonamigo (2017) discutem, avaliando que as emissoras passaram a enfrentar situações novas rela- 
cionadas ao fazer jornalístico, que partem do próprio estabelecimento de um fluxo de trabalho, passam pela necessidade de atualização técnica dos profissionais, até o entendimento do que ofertar de conteúdo e como se comportar diante da interação com os telespectadores.

Se antes, o telespectador assistia passivamente tudo o que era veiculado na tela do seu aparelho, agora, a internet permite que ele tenha voz. Ele pode, por meios de redes sociais, por exemplo, afirmar seu desconforto, denunciar um conteúdo, corrigir uma informação (RODEMBUSCH; BONAMICO, 2017). Entretanto, esse poder pode ser usado nocivamente, como será discutido mais adiante.

O jornalismo passa por uma crise do próprio fazer jornalístico, do que é a profissão e quem pode exercê-la (DANTAS et al., 2017; MCCHESNEY, 2016). A rapidez das mudanças tecnológicas atravessa o trabalho dos indivíduos na sociedade e nas organizações. Com uma câmera na mão, qualquer um pode noticiar um fato imediatamente quando acontece, de repente um cidadão comum está na posição de um repórter. Sem falar nos youtubers, que se comunicam com milhões de pessoas em seus canais e são uma espécie de apresentadores do formato de programa que optaram por veicular nas plataformas digitais (LINDÉN, 2017; SIQUEIRA, 2017; WOLFF, 2015).

Outro ponto crítico do setor, trata-se da regulamentação. No Brasil, desde a década de 1940, paralelo aos esforços de profissionalização, havia grupos que discordavam quanto à exigência do diploma. Em 2001, deu-se início a um processo movido pelo Sindicato das Empresas de Rádio e Televisão do Estado de São Paulo (SERTESP) e o Ministério Público Federal (MPF) solicitando ao governo que retirasse a obrigatoriedade do diploma, o que acabou acontecendo em 2009 (DANTAS; OLIVEIRA FALCÃO, 2018).

Aparentemente, essa profissão sempre foi acompanhada de dilemas sobre o fazer - quem pode exercer, como pode, etc. -, e o progresso tecnológico vem ampliando essas questões, que culminam na precarização da atividade. Para Dantas et al. (2017) a precarização do 
trabalho do jornalista se manifesta por meio do acúmulo de funções. O novo profissional é o jornalista multifunção, que executa todas as etapas do processo. A precarização também se dá por meio dos prazos cada vez mais apertados para entregarem suas atividades e das posturas gerenciais das empresas de comunicação de desvalorização do profissional, por exemplo, deixando transparecer a todo momento como essa mão de obra pode ser facilmente substituída.

\section{O último prego no caixão: Reforma Trabalhista e Violência Política}

Como se não bastasse o profundo impacto causado pela revolução digital no trabalho do jornalista, as ameaças trazidas pela reforma trabalhista (KREIN, 2018) e um preocupante aumento da violência da extrema direita contra estes profissionais (RIOS; BRONOSKY, 2020), advinda da radicalização no clima político do país, parecem enterrar o último prego no caixão do trabalho do telejornalismo, especialmente nas emissoras tradicionais.

A reforma trabalhista brasileira, em vigor desde 2017, impôs mudanças que atingiram em cheio os trabalhadores e, dentre eles, os jornalistas. A reforma é a maior mudança na legislação do trabalho dos últimos setenta anos. Diminuiu e eliminou não só inúmeros direitos e garantias conquistadas pelo trabalhador brasileiro ao longo de quase um século, como diminuiu muito o poder tanto dos sindicatos quanto da Justiça do Trabalho (KREIN, 2018). Em muitos aspectos fundamentais da relação de trabalho, como a remuneração, jornada de trabalho e do tipo de contrato de trabalho, a reforma abriu a possibilidade de negociação individual do trabalhador com o empregador, sem necessidade de participação do sindicato, o que enfraquece sobremaneira o poder de barganha do trabalhador.

Por tratar-se de um cenário recente, não foram encontrados estudos que apontem os impactos da reforma trabalhista nas atividades dos jornalistas. Para os jornalistas entrevistados desta pesquisa, o enfraquecimento dos sindicatos levou ao aumento da jornada de 
trabalho. Aparentemente, os acordos individuais se tornaram práticas nas emissoras de TV imediatamente após a reforma, evidenciando aos jornalistas a precarização da profissão.

Paralela às mudanças trazidas pela reforma trabalhista há também a intensificação da violência por parte de grupos políticos contra a classe. O estudo de Rios e Bronosky (2020) indica a multiplicação de atos violentos contra os jornalistas, sendo a internet, por meio das redes sociais, instrumento de fomento para a prática de tais atos. Relacionados a essa violência estariam: o cenário de radicalização política; o ingresso de novos atores entre aqueles que se sentem autorizados a atacar física e verbalmente jornalistas; e as contribuições do forte contexto de midiatização (proliferação das informações entre as mídias).

Deste modo, à insegurança quanto ao futuro do jornalismo, trazida pela revolução digital e pela reforma trabalhista, soma-se a insegurança do próprio exercício da profissão. O jornalista, de certa forma, sempre precisou lidar com algum risco (RIOS; BRONOSKY, 2020), por exemplo, ao atuar na linha investigativa ou em regiões de conflitos armados. Mas, se antes a preocupação esteve relacionada à investigados ou envolvidos de alguma forma no processo de construção da notícia, hoje, o simples fato de ser jornalista, ou trabalhar em determinada empresa do setor, tem afligido profissionais.

De acordo com a Federação Nacional de Jornalistas (FENAJ, 2020), desde 2013, o contexto de violência contra jornalistas vem se modificando. Em apenas um ano houve um crescimento de mais de 50\% nos casos: 208 em 2019 contra 135 casos em 2018. Segundo o levantamento, o presidente Jair Bolsonaro foi responsável, sozinho, por $58,17 \%$ dos ataques (FENAJ, 2020). Trata-se, então, de uma violência política radicalizada pela extrema direita do país. A literatura acerca dessa temática é bastante escassa, talvez porque o alastramento desses ataques vem se intensificando nos últimos anos.

Percebe-se que o universo do trabalho jornalístico vai se configurando e reconfigurando em meio à revolução digital. Somados às transfor- 
mações trazidas pela Indústria 4.0, novos fatores impactam a carreira jornalística, intensificando sua vulnerabilidade (PITHAN, VACLAVIK; OLTRAMARI, 2020), como a reforma trabalhista e a violência política.

\section{Metodologia}

A estratégia desta pesquisa foi qualitativa e sua natureza pode ser caracterizada por descritiva (BAUER; GASKELL, 2017). Trata-se de um estudo de casos múltiplos, compreendendo como sujeitos de pesquisa jornalistas e dirigentes sindicais, abordando o trabalho de jornalistas em dois casos: em emissoras de televisão tradicionais e da internet (BARDIN, 2011).

Os sujeitos da pesquisa foram 18 jornalistas, com faixa etária de 22 a 46 anos, que atuam em emissoras de televisão em Minas Gerais - 8 jornalistas de emissoras tradicionais e 10 jornalistas de emissoras da internet. Também foram entrevistados 7 dirigentes sindicais que atuam nas 5 regiões brasileiras (Norte, Nordeste, Centro-Oeste, Sudeste e Sul), em sindicatos de jornalistas dos seguintes estados: São Paulo, Espírito Santo, Pará, Ceará, Distrito Federal, Minas Gerais e Paraná. Os sindicatos de jornalistas são de abrangência estadual.

A inclusão de dirigentes sindicais nos sujeitos de pesquisa se deu a partir dos depoimentos dos jornalistas, que relataram alterações no trabalho após a reforma trabalhista, mas não conseguiram explicar questões relacionadas aos acordos coletivos negociados e assinados entre os sindicatos e as emissoras. Os jornalistas também mencionaram o enfraquecimento dos sindicatos. Sendo assim, percebeu-se a necessidade de inclui-los neste estudo. Utilizou-se ainda a técnica de snowball sampling, chamada no Brasil de técnica da "Bola de Neve" (VINUTO, 2016) para encontrar ambos os entrevistados: jornalistas e dirigentes sindicais. No caso dos jornalistas, as redes sociais também foram utilizadas como forma de contato.

Ao investigar profissionais jornalistas que trabalham em emissoras tradicionais e emissoras da internet, este estudo se baseou na dife- 
renciação apresentada pela literatura (FERREIRA; BIANCHETTI, 2018). Ou seja, os repórteres das emissoras da internet entrevistados nesta pesquisa trabalham em organizações que surgiram na internet. Embora possa haver também diferença nas atividades de jornalistas de emissoras tradicionais ao produzir conteúdo específico para o portal desta emissora, ou seja, para a web, a ideia é apontar tais diferenças no que diz respeito à TVs tradicionais e TVs da internet.

Desta forma, os jornalistas de emissoras tradicionais são aqueles que trabalham em emissoras de canais abertos, as chamadas "grandes emissoras". Os profissionais de emissoras da internet trabalham, em geral, para prefeituras, câmaras municipais, times de futebol, entre outros, que passaram a produzir e veicular conteúdo audiovisual em plataformas digitais, inaugurando seus canais de TV da internet, geralmente identificados com o próprio nome da instituição, por exemplo: "TV Câmara (de tal cidade)".

Os pesquisadores optaram pela entrevista semiestruturada, para conseguir explorar detalhadamente os relatos dos entrevistados. Para a definição da quantidade de entrevistas foi utilizada a saturação teórica (BAUER; CASKELL, 2017). Um roteiro foi elaborado, a partir da literatura da temática, para orientar a conversa, sabendo-se que outras questões poderiam emergir de acordo com os relatos dos entrevistados.

A partir da primeira entrevista, para direcionar melhor os relatos, o roteiro foi readaptado. As 18 entrevistas dos jornalistas aconteceram fora de seus locais de trabalho, com duração média de 1 hora cada, entre março e junho de 2019. A maioria foi gravada com autorização dos entrevistados, mas alguns preferiram que a gravação não ocorresse, alegando terem a voz conhecida por estarem todos os dias na TV. Nesses casos, os pesquisadores anotaram as respostas. Os dirigentes sindicais foram entrevistados por telefone (5) e 2 por email. A duração da entrevista por telefone teve em média 30 minutos.

As entrevistas foram transcritas e os dados obtidos foram submetidos à análise de conteúdo, do tipo Análise Categorial Temática 
(BARDIN, 2011), possibilitando inferências sobre a fonte e a identificação de categorias de análise.

Para preservar a identidade dos participantes e ilustrar os dados coletados, na análise de dados que se segue optou-se, ao se referir a cada sujeito, pela utilização da sigla "JT", quando o entrevistado for jornalista de uma emissora tradicional, e, em seguida o número da entrevista na ordem em que ocorreu, e pelas letras "Jl", quando for de emissora da internet, também seguida do número da entrevista na ordem em que ocorreu. Os dirigentes sindicais são apresentados pela sigla "DS", seguida da sigla da localidade que representa: SP, $E S, P A, C E, D F, M G$ ou PR.

\section{Análise de Dados}

A partir dos dados coletados foi possível identificar as seguintes categorias de análise: Impactos da Indústria 4.0 no Trabalho dos Jornalistas; Reforma Trabalhista: Jornada de Trabalho e Remuneração; Da Ameaça à Violência: um Futuro Fora de Foco.

\section{Impactos da Indústria 4.0 no Trabalho dos Jornalistas}

Os entrevistados de emissoras tradicionais descreveram novas atividades sendo implementadas em suas rotinas de trabalho, corroborando a literatura (DANTAS et al., 2017). Ainda assim, possuem uma rotina com menos atribuições do que os que trabalham em emissoras da internet. Por exemplo, em emissoras tradicionais, a pauta é feita pela produção. Os repórteres, para se dirigem ao local em que farão a reportagem, são acompanhados por uma equipe, geralmente composta por cinegrafista, auxiliar e motorista. A montagem da matéria é realizada por editores de texto e vídeo. Junto ao repórter há operadores de áudio, de vídeo e diversos outros profissionais envolvidos: “Nós que trabalhamos há mais tempo em televisão, percebemos redução de funcionários, menos contratações. Mas ainda trabalhamos com gente capacitada em cada etapa do processo" (JT5). 
Uma realidade bem diferente da vivenciada por jornalistas de emissoras da internet. Os depoimentos desses profissionais descrevem o "novo jornalista", com multifunção, conforme abordado pela literatura (RODEMBUSCH; BONAMICO, 2017). Os entrevistados declararam desempenhar diversas funções, muitas vezes todas, como edição de vídeo, produção, filmagem, entre outras: “Eu levo a minha mochila para o estádio, tiro o tripé e a câmera, faço as imagens, a passagem (aparição do repórter), volto para a redação, edito e coloco no ar. Não tem motorista, editor, nada disso..." (Jl14).

Apesar de contarem com uma estrutura melhor, os profissionais das emissoras tradicionais apontam mudanças nas atividades: “Agora tá uma cobrança muito grande para que a gente faça stories, conteúdos dos nossos celulares, postagens nas redes, coisas que antes não existia" (JT3); “... acaba que a gente trabalha muito mais” (JT4). Trata-se da inserção de novas atividades, motivada pela web (DANTAS et al., 2017).

Sobre esse aspecto, os dirigentes sindicais confirmaram que o setor (TVs tradicionais) vem enfrentando ao longo dos anos redução de profissionais e ampliação de funções (PITHAN, VACLAVIK; OLTRAMARI, 2020): “Até 2017, as homologações das demissões eram feitas nos sindicatos... então, posso te dizer que ano após ano crescia consideravelmente esse número" (DSMG); "Temos visto, ao longo do tempo, a desvalorização do jornalista, o acúmulo de função, as demissões em massa" (DSDF).

Observa-se que os relatos de quem trabalha nas emissoras tradicionais, em suma, sugerem que para se manter na profissão, o jornalista terá conseguir desenvolver várias funções, corroborando a literatura (FERREIRA; BIANCHETTI, 2018): "Precisamos nos preparar porque no futuro acho que o jornalista não vai ter mais uma emissora fixa, uma carteira assinada, talvez ele vai vender conteúdo, vai ter que se adaptar ao meio" (JT2); "Tecnicamente, o futuro é ter essa coisa da multiplicidade ali da função" (JT7). No entanto, o que tratam como futuro já se constitui prática para profissionais das emissoras da internet. 
Os entrevistados das emissoras da internet, em geral, apontaram a estrutura enxuta, ou a falta dela, como diferença importante em relação às emissoras tradicionais e fator determinante para o desenvolvimento de múltiplas tarefas: "A câmera que a gente usa pra filmar é totalmente defasada” (J112); “Muitas vezes falta o básico, mas temos que nos virar e a gente faz dar certo" (JI11). Relatos que apontam para a precarização da profissão, conforme discutido pela literatura (POCHMANN, 2016; SOUSA, 2019).

Sobre essas emissoras da internet, os dirigentes sindicais abordaram a dificuldade de fiscalização: "É praticamente impossível, o registro não é de televisão ou veículo de imprensa, são organizações que já existem e começam a fazer TV, mas não precisam de concessão" (DSCE); “Os jornalistas nem são contratados como jornalistas, são analistas de alguma coisa, geralmente. Não tem convenção, não tem nada" (DSPR).

Abre-se um parênteses para destacar que os jornalistas das emissoras da internet, declararam, especialmente quem já havia trabalhado em emissoras tradicionais, uma maior liberdade encontrada nas emissoras da internet: "Ao mesmo tempo que a gente faz tudo, a gente também tem mais liberdade na linguagem, na condução da notícia" (JI8); “A TV da internet já te possibilita uma linguagem mais solta, mais jovem" (Jl11). Essa maior liberdade na condução do trabalho pareceu ser um fator de realização para os jornalistas da internet. Mesmo com a precarização, que ficou ainda mais evidente ao se observar remuneração e jornada de trabalho, conforme a seguir.

\section{Em Pauta, a Reforma Trabalhista: Jornada de Trabalho e Remuneração}

Em relação à jornada de trabalho, os entrevistados das emissoras tradicionais declararam trabalhar em média 8 horas por dia, 6 dias por semana. De acordo com a maioria deles e corroborando a literatura (KREIN, 2018), após a reforma trabalhista, a jornada aumentou e não houve alteração na remuneração. 
Os jornalistas disseram que antes da reforma trabalhavam cinco horas por dia; se precisassem trabalhar mais duas, o que não era tão frequente, recebiam como horas extras. Agora, trabalham duas horas a mais todos os dias, em um sistema de banco de horas de compensação, sem o pagamento em dinheiro das horas extras: “Vieram com um acordo individual de banco de horas e de jornada e a gente teve que assinar porque não tem saída, não é explícito 'você assina ou está demitida', mas a gente sabe que é isso" (JT1).

Os dirigentes sindicais explicaram essas informações sobre os efeitos da reforma trabalhista (KREIN, 2018; PITHAN, VACLAVIK; OLTRAMARI, 2020) na precarização da classe jornalística: “A jornada de trabalho de cinco horas dos jornalistas é estabelecida pela CLT e a mesma lei também previa a possibilidade de elevação da jornada para sete horas diárias, mas por convenção coletiva" (DSLO); "Tudo era definido por convenção coletiva. Para TVs, as horas extras eram em caso de catástrofes ou situações emergenciais, se fossem aos finais de semana obrigatoriamente tinham de ser remuneradas" (DSPA); "Por isso, eles sentiram no bolso. Na prática, essa redução que eles mencionam é justamente o não pagamento das horas extras que hoje eles fazem diariamente e acabam compensando tudo em banco de horas, já que assinaram o acordo com a empresa" (DSMC).

O enfraquecimento dos sindicatos, um dos efeitos da reforma trabalhista (KREIN, 2018), ganhou destaque nas declarações dos entrevistados: "Com a reforma trabalhista, perdemos o sindicato, não há fiscalização, nem denúncias. A justiça do trabalhou piorou, se perde tem que pagar, então quem quer arriscar? Não há emprego, tem que se submeter, o chefe fala 'se você não quer, tem quem queira'" (JT10).

Percebeu-se, por meio dos depoimentos dos profissionais atuantes em emissoras tradicionais, que estas organizações, após a reforma trabalhista, rapidamente colocaram em prática o banco de horas por acordo individual, sem a intermediação do sindicato. Isso é mostrado pela literatura (DANTAS et al., 2017; KREIN, 2018) como elemento de 
precarização do trabalho, uma vez que, sendo a empresa a parte mais forte das relações de trabalho, ela impõe sua posição ao trabalhador que, individualmente, sem outra organização forte que o apoie (o sindicato), aceita para não ficar desempregado: "Os direitos do trabalhador ficam suprimidos por um 'acordo individual' direto com a empresa” (DSCE); “Todas nossas conquistas estão se desfazendo, o jornalista está sentindo no bolso e na saúde, trabalhando muito mais horas e recebendo menos por essas horas" (DSMC).

Em geral, os jornalistas das emissoras tradicionais destacaram como impactos após a reforma trabalhista: o acordo individual de jornada, a ausência do Sindicato, o aumento da pressão por resultados e o clima hostil, em que a todo o momento se sinaliza a instabilidade daquele emprego.

Por sua vez, os entrevistados das emissoras da internet informaram jornadas de trabalho bem superiores às mencionadas acima, indicando precarização ainda maior que na TV tradicional (DANTAS et al., 2017; RODEMBUSCH; BONAMIGO, 2017). Os relatos apontam para uma média de 12 horas por dia, com situações que ainda extrapolam esse número, 6 vezes na semana ou todos os dias. Apenas dois desses profissionais têm carteira assinada, três assinaram contratos temporários (que podem ou não ser renovados a critério do contratante) e cinco são profissionais autônomos, prestam serviços para emissoras da internet como Pessoa Jurídica, denotando a “pjotização” (KREIN, 2018).

Os dois profissionais que têm carteira assinada atuam em organizações de pequeno porte em que não há registro de ponto eletrônico, o que facilita as jornadas excessivas, conforme depoimento: “Eu produzo, faço as imagens, edito, finalizo, tudo... não tem muito controle do horário, a gente tem que dar conta... depois você preenche a folha como se trabalhasse 8 horas, mas fica 10, 12... e ainda leva para terminar em casa" (JI14).

Fica claro como o jornalista da TV da internet tem um trabalho ainda mais precário por estar na ponta do processo de revolução digital, 
conforme discutido na literatura (LEME; RODRICUES, 2017; PATRICK; ELKS, 2015; POCHMANN, 2016). O mesmo acontece com os jornalistas em contrato temporário: "A gente quer mostrar serviço, para conseguir uma colocação, uma renovação... então a gente fica até bem mais tarde, final de semana, mas na folha a gente não coloca isso" (JI11).

Sobre isso, novamente os dirigentes sindicais afirmaram a dificuldade de fiscalização e denunciaram o excesso de horas trabalhadas na jornada: "pelos dados coletados do Caged-IBCE de 2017, aqui no Ceará, os jornalistas têm a maior carga horária de trabalho do país, trabalham 11 horas a mais que a jornada legal e três horas acima da média nacional” (DSCE); “A gente não consegue fiscalizar e nem adiantaria porque a exploração está sendo legalizada por meio das novas regras trabalhistas" (DSLO).

Os autônomos, embora reconhecendo que não há muitas oportunidades de emprego na área, consideram o empreendedorismo uma opção que fızeram, corroborando a literatura quando trata a distorção do termo (PATRICK; ELKS, 2015): “Optei por abrir minha empresa e escolher o que eu faço..." (JI17); "Eu decidi sair da emissora tradicional porque a internet é o futuro, a possibilidade de ganho é maior, além de você escolher sobre o que falar..." (Jl13).

Apesar dessas declarações, notou-se precarização. Por exemplo, esses profissionais têm jornadas de trabalho bem superiores às dos demais: "É quase full-time, para quem trabalha por conta própria não tem folga, nem fim de semana" (JI13). Ou seja, ainda que tratem como "escolha" profissional, a realidade aponta para um trabalho mais precário, no formato "uberização" (LEME; RODRICUES, 2017; PINHEIRO, DE PAULA SOUZA; GUIMARÃES, 2020; POCHMANN, 2016).

Mais precário ainda ao considerar a remuneração (Tabela 1). Os profissionais das emissoras tradicionais têm ganhos mais elevados que os da internet. Sendo assim, a pejotização, conforme abordado pela literatura (KREIN, 2018), traz essa aparência de empreendedorismo, mas pode significar precarização, pois, para se ter uma renda 
razoável, é preciso trabalhar muito mais (o tempo todo) e desempenhar todo tipo de função.

Tabela 1: Jornada de Trabalho e Remuneração nas emissoras tradicionais e da internet 2019

\begin{tabular}{|c|c|c|c|c|}
\hline Nome & Tipo de TV & $\begin{array}{l}\text { Atividades que } \\
\text { desempenha } \\
\text { e Regime de } \\
\text { Contratação }\end{array}$ & $\begin{array}{c}\text { Remuneração } \\
\text { mensal } \\
\text { aproximada }\end{array}$ & $\begin{array}{c}\text { Jornada } \\
\text { semanal } \\
\text { média }\end{array}$ \\
\hline JT1 & Tradicional & Repórter / CLT & $4.200,00$ & 48 \\
\hline JT2 & Tradicional & Repórter / CLT & $4.200,00$ & 48 \\
\hline JT3 & Tradicional & Repórter / CLT & $5.000,00$ & 40 \\
\hline JT4 & Tradicional & Repórter / CLT & $3.800,00$ & 44 \\
\hline JT5 & Tradicional & Repórter / CLT & $4.200,00$ & 48 \\
\hline JT6 & Tradicional & Repórter / CLT & $4.800,00$ & 48 \\
\hline JT10 & Tradicional & Apresentador/ CLT & $4.800,00$ & 48 \\
\hline JT7 & Tradicional & Repórter/ CLT & $4.800,00$ & 44 \\
\hline Jl8 & Internet & $\begin{array}{l}\text { Todas as funções/ } \\
\text { PJ- Autônomo }\end{array}$ & $4.000,00$ & 72 \\
\hline JI9 & Internet & $\begin{array}{l}\text { Todas as funções/ } \\
\text { PJ- Autônomo }\end{array}$ & $4.000,00$ & 72 \\
\hline $\mathrm{Jl11}$ & Internet & $\begin{array}{l}\text { Todas / Cont. } \\
\text { Temporário }\end{array}$ & $2.800,00$ & 48 \\
\hline Jl12 & Internet & $\begin{array}{l}\text { Todas / Cont. } \\
\text { Temporário }\end{array}$ & $2.800,00$ & 48 \\
\hline $\mathrm{Jl13}$ & Internet & $\begin{array}{l}\text { Todas as funções/ } \\
\text { PJ- Autônoma }\end{array}$ & $4.000,00$ & 60 \\
\hline Jl14 & Internet & $\begin{array}{c}\text { Todas as funções/ } \\
\text { CLT }\end{array}$ & $3.000,00$ & 48 \\
\hline Jl15 & Internet & $\begin{array}{c}\text { Todas as funções/ } \\
\text { CLT }\end{array}$ & $3.000,00$ & 48 \\
\hline JI16 & Internet & $\begin{array}{l}\text { Todas / Cont. } \\
\text { Temporário }\end{array}$ & $2.800,00$ & 48 \\
\hline JI17 & Internet & $\begin{array}{l}\text { Todas as funções/ } \\
\text { PJ- Autônomo }\end{array}$ & $3.000,00$ & 72 \\
\hline $\mathrm{Jl} 18$ & Internet & $\begin{array}{l}\text { Todas as funções/ } \\
\text { PJ-Autônomo }\end{array}$ & $3.000,00$ & 72 \\
\hline
\end{tabular}

Fonte: elaborada pelos autores a partir dos dados da pesquisa. 
Os entrevistados das emissoras da internet que trabalham sob regime de CLT recebem em torno de $R \$ 2.800,00$, e isso trabalhando mais tempo do que nas TVs tradicionais, enquanto o salário mais baixo entre os de emissoras tradicionais, que também trabalham sob esse regime, é $\mathrm{R} \$ 3.800,00$. Aqueles que têm contrato temporário com emissoras da internet têm ganhos ainda mais baixos, $R \$ 2.800,00$, e sem as mesmas garantias trabalhistas que os que estão sob o regime de CLT. Os profissionais autônomos, embora apresentem remuneração um pouco maior que seus colegas de emissoras da internet, recebem menos que os jornalistas que trabalham em emissoras tradicionais e não têm direitos trabalhistas garantidos.

Em suma, percebeu-se que para os jornalistas das emissoras da internet, a precarização (KREIN, 2018) é mais contundente, embora também seja sentida pelos profissionais das emissoras tradicionais, principalmente após a reforma trabalhista.

\section{Da Ameaça à Violência: um futuro fora de foco}

Os jornalistas enfatizaram o temor frente a diferentes formas de violência, física e virtual. Os profissionais das emissoras tradicionais destacaram o medo de exercerem a profissão por causa da intensificação dos ataques dos telespectadores, corroborando a literatura (RIOS; BRONOSKY, 2020). Alguns foram impedidos de trabalhar diante de ameaças e agressões verbais, que por pouco não se tornaram físicas: "Saímos rapidamente, eu e o cinegrafista, porque um começou a xingar e foi influenciando outros, aí vimos que a situação sairia do controle e nos retiramos" (JT6); "Uma colega foi empurrada, caiu e se machucou na mesma semana, tudo em frente às câmeras. E de repente, estava acontecendo comigo, um grupo ameaçando. Preferi ir embora." (JT3).

Os entrevistados disseram que acreditam que a polarização política - mencionada por Rios e Bronosky (2020) - e a impunidade são as principais razões para o que vem acontecendo: “As pessoas são enco- 
rajadas porque não há punição, elas têm tanta certeza da impunidade que fazem isso diante das câmeras" (JT2).

A discussão sobre o crescimento da violência contra jornalistas ainda é recente. Entre os fatores associados à essa violência, Rios e Bronosky (2020), conforme mostrado, apontaram a radicalização dos atos agressivos; a polarização política, o ingresso de novos atores nesses ataques e a midiatização, que permite a propagação desses atos violentos. Este estudo acrescenta outro fator, a impunidade. Conforme depoimentos, além de se sentirem autorizados, ao verem representantes de instituições e agentes públicos praticarem tais atos, indivíduos se sentem também encorajados quando percebem a impunidade diante da violência praticada. Dos 18 jornalistas entrevistados, 14 destacaram a impunidade como incentivo aos agressores.

Observou-se nos relatos o desânimo com a profissão motivado por esse fator: "A gente sempre se orgulhou em estar todos os dias na casa das pessoas, ser reconhecido. Agora, parece que é ruim ser jornalista, não é tão legal aparecer, ser conhecido, porque você pode ser atacado por isso" (JT2); "Tem muita gente saindo... você vê aí grandes nomes do jornalismo migrando para o entretenimento, ou para a internet" (JT7).

Os entrevistados das emissoras da internet também relataram ataques, mas por meio das redes sociais: "A gente recebe críticas e até ofensas nas redes sociais, falam da aparência, de tudo... são os haters..." (JI14); “Ah é muito comum, as pessoas se escondem por trás de perfis falsos para atacar..." (Jl15).

Embora tenham comentado sobre isso, diferente dos profissionais de emissoras tradicionais, os jornalistas de emissoras da internet declararam não se sentirem ameaçados no exercício da profissão e não mencionaram agressões físicas: "Quando eu trabalhei em TV normal [tradicional] eu tinha medo sim porque você é reconhecido na rua toda hora, e sempre tem algum louco... hoje, sou bem menos abordada, de certa forma me sinto mais segura" (Jl13). A Entrevistada 13 trabalhou muito tempo em uma emissora tradicional e, ao comparar com a in- 
ternet, nesse aspecto da violência, ela diz se sentir mais segura. Parece contraditório porque a mesma internet que intensifica a violência - já que aumenta a interação com o público, muitos usam o termo "aproxima" o público- é justamente o lugar que "distancia" - fisicamente - esse público do jornalista, trazendo a sensação de uma menor probabilidade de agressão física.

Em geral, os profissionais de ambas emissoras disseram que não têm grandes expectativas e cogitam abandonar a profissão, conforme abordado pela literatura (DANTAS et al., 2017; PITHAN, VACLAVIK; OLTRAMARI, 2020): "Eu penso em mudar de área, fazer outra coisa... nossa profissão caiu em descrédito" (Jl17); “Temos que arrumar outra forma de sobreviver e fazer jornalismo independente" (JT1).

Em síntese, os dados mostram que a contemporaneidade tem modificado as práticas profissionais dos jornalistas e o futuro da profissão é preocupante para a classe, que tem dificuldade de encontrar um lugar no horizonte, aparentemente tão incerto. O aumento nas atividades e funções, as novas negociações para a remuneração, a pejotização, a insegurança quanto a manutenção do emprego, e até quanto à integridade física do trabalhador, apontam para a precarização dessa atividade.

\section{Considerações Finais}

Os dados mostraram que a web tem impulsionado transformações nas atividades dos jornalistas de emissoras tradicionais e impõe novos modelos de trabalho. Ou seja, o jornalista caminha para se tornar o novo profissional que a contemporaneidade impõe. O que atua nas emissoras da internet já é esse novo profissional: multifuncional, com pouca ou nenhuma garantia trabalhista, remuneração menor e jornada de trabalho maior.

Cumprindo o objetivo deste estudo, de discutir as atividades e os desafıos de jornalistas que atuam em frente às câmeras nestas emissoras, diante da revolução digital, da reforma trabalhista e do cenário 
político brasileiro atual, observou-se que todos esses elementos contribuem para a crise do setor e a precarização da profissão.

Os jornalistas das emissoras tradicionais destacaram como impactos após a reforma trabalhista: novos acordos individuais com aumento de jornada e reflexos negativos na remuneração, a ausência do Sindicato, o aumento da pressão por resultados e o clima hostil, em que a todo o momento se sinaliza a instabilidade daquele emprego. Os dirigentes sindicais de todo o país confirmaram a precarização do setor, que já vinha ocorrendo com a revolução digital e se agravou após a reforma trabalhista. Desta forma, uma das contribuições deste estudo foi apresentar os impactos da reforma trabalhista nessa atividade, uma discussão ainda escassa na literatura.

Além da insegurança relacionada à manutenção do emprego, destacou-se também à insegurança quanto à própria integridade física dos profissionais. A onda de ataques violentos de telespectadores se apresentou como um fator de impacto na carreira dos telejornalistas, especialmente de emissoras tradicionais. A web se tornou espaço para atos de violência e propagação de supostas razões que validem tais ataques. Os profissionais das emissoras da internet, embora não se sintam ameaçados no exercício da profissão, também relatam violência, agressões e ofensas por meio das plataformas digitais.

A literatura indicou alguns fatores para este cenário de violência, e este estudo avança ao acrescentar mais um fator: a impunidade. Sendo assim, leis e punições mais rigorosas, assim como medidas de conscientização poderiam auxiliar no combate à violência contra jornalistas. Violência que fere a Constituição em duas frentes: no direito ao trabalho e no direito ao acesso à informação. Ao impedir o trabalho do jornalista, nega-se à população o acesso à informação que por ele seria prestada. Em uma análise mais profunda, pode-se dizer que é um ataque à democracia, já que a informação é fundamental para exercício da cidadania. 
Para os profissionais das emissoras da internet, apesar da precarização - multifuncionalidade, menor remuneração, jornadas maiores e ausência de garantias trabalhistas -, a web possibilita exercer mais a criatividade e a liberdade na linguagem, o que se mostrou importante para eles. No entanto, foram percebidos aspectos da uberização, já que se autodefinem empreendedores, mas trabalham muito mais, recebendo menos e sem garantias trabalhistas.

Em suma, jornalistas de ambas as emissoras sabem que o trabalho foi modificado, ou melhor, precarizado. Muitos cogitam o abandono da profissão e outros o autoemprego e empreendorismo. O clima é de desesperança e frustração quanto ao futuro na profissão.

Esta pesquisa contribui ao apresentar e comparar dados sobre o trabaIho dos telejornalistas de emissoras tradicionais e da internet. Sobre esta última, em especial, há pouquíssimas discussões na literatura. O presente estudo avança também ao ampliar o debate acerca da precarização da profissão e dos novos modelos de trabalho na contemporaneidade, abordando transformações já decorrentes da recente reforma trabalhista no Brasil. Contribui, ainda, ao contemplar a violência como fator que intensifica a crise no trabalho do jornalista, também raro na literatura. Dentro disso, avança ao incluir a impunidade como razão para essa violência.

Apresenta-se como limitação deste trabalho o número de jornalistas entrevistados e todos eles atuarem em emissoras de Minas Gerais. Recomendam-se, então, novos estudos com mais sujeitos de pesquisa e maior abrangência.

\section{Referências}

BARDIN, Laurence. Análise de conteúdo (Edições 70). Lisboa. Portugal, 2011. BAUER, Martin W.; CASKELL, George. Pesquisa qualitativa com texto, imagem e som: um manual prático. Editora Vozes Limitada, 2017.

DANTAS, Juliana Bulhões Alberto; de OLIVEIRA FALCÃO, Priscila Dalva. Mídia Ninja, Jornalismo Cidadão Online e a Profıssionalização do Jornalista no Brasil. Âncora: Revista Latino-Americana de Jornalismo, 5(1), 2018. 
DANTAS, Juliana Bulhões Alberto; PINHEIRO, Elton Bruno Barbosa; DA SILVA, Vinícius Pedreira Barbosa; BELTRAME, Vanessa; DAVID, Hadassa Ester. Precarização e Mudanças Estruturais no Jornalismo: Reflexões Sobre Tendências Teóricas. Mediapolis: Revista de Comunicação, Jornalismo e Espaço Público, n. 5, p. 39-49, 2017.

DUNN, Michael. Digital work: New opportunities or lost wages?. American Journal of Management, v. 17, n. 4, 2017.

FERREIRA, Simone de Lucena; BIANCHETTI, Lucídio. Televisão on-line e possibilidades para a educação interativa. Revista Educação e Cultura Contemporânea, v. 2, n. 3, p. 109-124, 2018

FENAJ. Relatório da FENAJ mostra crescimento da violência contra jornalistas. Publicado em 16 jan. 2020. Disponível em: fenaj.org.br - Acesso em 12 fev. 2020. KREIN, José Dari. O desmonte dos direitos, as novas configurações do trabaIho e o esvaziamento da ação coletiva: consequências da reforma trabalhista. Tempo Social, v. 30, n. 1, p. 77-104, 2018.

LEME, Ana Carolina Reis Paes; RODRIGUES, Bruno Alves. Tecnologias Disruptivas e a exploração do trabalho humano. CEP, v. 1224, p. 003, 2017.

LINDÉN, Carl-Gustav. Algorithms for journalism: The future of news work. The journal of media innovations, v. 4, n. 1, p. 60-76, 2017.

MCCHESNEY, Robert W. Journalism is dead! Long live journalism?: Why democratic Societies will need to subsidise future news production. Journal of Media Business Studies, v. 13, n. 3, p. 128-135, 2016.

MÉDOLA, Ana Sílvia Lopes Davi; SILVA, Elissa Schpallir. Segunda tela e a reconfiguração das práticas comunicacionais no processo de fruição de televisão. Revista FAMECOS: mídia, cultura e tecnologia, v. 22, n. 1, p. 145-164, 2015.

PATRICK, Holly; ELKS, Kate. From battery hens to chicken feed: The perceived precarity and identity of Australian journalists. Asia Pacific Journal of Arts and Cultural Management, v. 12, n. 1, 2015.

PINHEIRO, Silvia Silva Martins; DE PAULA SOUZA, Marcia; GUIMARÃES, Karoline Claudino. Uberização: a precarização do trabalho no capitalismo contemporâneo. Serviço Social em Debate, v. 1, n. 2, 2020.

PITHAN, Liana Haygert; VACLAVIK, MARCIA CRISTIANE; OLTRAMARI, Andrea Poleto. Vulnerable careers: analysis of media layoffs as a turning point for journalists. Cadernos EBAPE. BR, v. 18, n. 1, p. 158-171, 2020. 
POCHMANN, MARCIO. Terceirização, competitividade e uberização do trabalho no Brasil. TEIXEIRA, MO; RODRICUES, H.; COELHO, EA (Ors.). Precarização e terceirização: faces da mesma realidade. São Paulo: Sindicato dos Químicos, p. 59-68, 2016.

RIOS, Aline; BRONOSKY, Marcelo. Violência contra jornalistas, ameaça à sociedade. Mosaico, v. 11, n. 17, p. 86-103, 2020.

RODEMBUSCH, Rodrigo Severo; BONAMICO, Daniela. The culture of participation in Brazilian public television: a study of the program Nation from TVE/ RS. EPTIC, v. 19, n. 3, p. 189-205, 2017.

SIMON, Luciana Galhardo Batista et al. A Profissão que Ficou para Trás? O Jornalista na Linha de Frente do Avanço Tecnológico. Gênero, notícia e transformação social, p. 170, 2019.

SIQUEIRA, Fabiana Cardoso. Telejournalism in Transformation: The Co-Production of New News-Values. Brazilian Journalism Research, v. 13, n. 2, p. 141-155, 2017.

SOUSA, Cleidianne Novais. Os mecanismos de precarização do trabalho no Brasil: terceirização e informalidade do trabalho. Cadernos CEPEC, v. 3, n. 1-6, 2019.

VINUTO, Juliana. A amostragem em bola de neve na pesquisa qualitativa: um debate em aberto. Temáticas, Campinas, v. 22, n. 44, p. 203-220, 2016.

WOLFF, Michael. Televisão é a nova televisão. Globo Livros, 2015.

\section{Notas}

1 Agradecimentos: CAPES e CNPQ.

2 Mestre e Doutoranda em Administração - PUC Minas. Brasil. ORCID 00000002-7807-7193. ericalimamidias@gmail.com

3 Doutora em Administração. Professora PPCA PUC Minas. Brasil. ORCID 00000001-8830-8170. cmmotasantos@gmail.com

4 Doutor em Administração. Professor PPCA PUC Minas. Brasil. ORCID 00000001-5439-2845. antoniocarvalhoneto1@gmail.com 


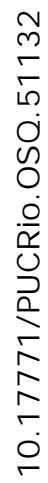

용 